Article

\title{
An Energetic Analysis of the Phase Separation in Non-Ionic Surfactant Mixtures: The Role of the Headgroup Structure
}

\author{
José Manuel Hierrezuelo, José Antonio Molina-Bolívar and Cristóbal Carnero Ruiz * \\ Department of Applied Physics II, Engineering School, University of Malaga, Malaga 29071, Spain; \\ E-Mails: jose.hierrezuelo@uma.es (J.M.H.);jmb@uma.es (J.A.M.-B.) \\ * Author to whom correspondence should be addressed; E-Mail: ccarnero@uma.es; \\ Tel./Fax: +34-951-952-295.
}

Received: 31 March 2014; in revised form: 24 June 2014 / Accepted: 30 July 2014 /

Published: 4 August 2014

\begin{abstract}
The main goal of this paper was to examine the effect of the hydrophilic surfactant headgroup on the phase behavior of non-ionic surfactant mixtures. Four mixed systems composed of an ethoxylated plus sugar-based surfactants, each having the same hydrophobic tail, were investigated. We found that the hydrophilicity of the surfactant inhibits the tendency of the system to phase separate, which is sensitive to the presence of $\mathrm{NaCl}$. Applying a classical phase separation thermodynamic model, the corresponding energy parameters were evaluated. In all cases, the parameters were found to depend on the type of nonionic surfactant, its concentration in the micellar solution and the presence of $\mathrm{NaCl}$ in the medium. The experimental results can be explained by assuming the phase separation process takes place as a result of reduced hydration of the surfactant headgroup caused by a temperature increase. The enthalpy-entropy compensation plot exhibits excellent linearity. We found that all the mixed surfactant systems coincided on the same straight line, the compensation temperature being lower in the presence of $\mathrm{NaCl}$.
\end{abstract}

Keywords: mixed micelles; phase separation; thermodynamic parameters; $n$-decyl- $\beta$-D-maltoside; $N$-decanoyl- $N$-methylglucamide; pentaoxyethylene monodecyl ether; hexaoxyethylene monodecyl ether

PACS Codes: 82.70.Uv; 82.60.Lf; 82.60.Fa 


\section{Introduction}

Among the different amphiphilic materials, non-ionic surfactants containing ethylene oxide chains, $-\left(\mathrm{OC}_{2} \mathrm{H}_{4}\right)_{m}$, as the hydrophilic group, compose an important class which finds extensive applications in industrial and pharmaceutical formulations due to their intriguing self-assembly properties [1-3]. Whenever the aqueous concentration of such non-ionic surfactants is above a certain critical value, the so-called critical micelle concentration (CMC), they, like other amphiphiles, form thermodynamically stables nanometer-sized assemblies called micelles. Aqueous solutions of ethoxylated non-ionic surfactants exhibit characteristic thermoreversible phase separation phenomena upon heating/cooling above/below a certain threshold temperature. In these systems, when the temperature is raised above a specific value, called the cloud point temperature $\left(T_{C P}\right)$, separation into two phases occurs. One of the phases is micellar-rich and the other is micellar-poor. The solution becomes cloudy as a result of phase separation; hence, the process in surfactant solutions is often referred to as the clouding phenomenon [4]. It has been well-established that phase separation is primarily due to the dehydration of the surfactant's hydrophilic groups when the temperature is increased. On one hand, this dehydration causes micellar growth and, on the other, it reduces intermicellar repulsive forces which finally leads to phase separation [3].

There are main two reasons why we need to understand and control the clouding phenomenon: firstly, because important advances have been made in the application of this phenomenon to several extraction and separation technologies [5] and, secondly, because in certain applications phase separation can negatively affect the performance of a surfactant-based formulation and should therefore be avoided [4,6]. Recent studies carried out in our laboratory [7,8] have demonstrated that it is possible to modulate the phase behavior of ethoxylated surfactants by mixing them with other non-ionic surfactants of a different nature. In particular, we are interested in carbohydrate-based surfactants, which are mainly characterized as having hydrophilic sugar headgroups in their polar moiety. The current interest in these products stems from their excellent ecological behavior, good performance and consumer health concerns, to mention but a few [9-11]. Separate studies with surfactants having the same nonpolar tail and varied polar headgroups as well as having the same headgroup with varying nonpolar tail in the presence and absence of additives are required to understand the involved physicochemical processes guiding the overall thermodynamics of clouding. In a previous publication we have studied the influence of the length of the hydrocarbon chain of sugar surfactants in phase separation of mixed micelles [8].

In the present work, we have studied the phase behavior of several binary mixtures of ethoxylated and sugar surfactants, in the presence and absence of $\mathrm{NaCl}$. Figure 1 shows the molecular structures of the surfactants studied. As can be seen, all of them have the same ten carbon hydrophobic chain length but their headgroups are chemically and structurally different. A flexible, and polymer-like headgroup characterizes the ethoxylated surfactants $\left(\mathrm{C}_{10} \mathrm{E}_{5}\right.$ and $\left.\mathrm{C}_{10} \mathrm{E}_{6}\right)$, whereas the sugar surfactants are mainly characterized by their numerous hydroxyl groups in the hydrophilic moiety.

One can also observe structural differences between the headgroups of the two sugar surfactants, whereas MEGA-10 exhibits an open structure, that of $\mathrm{C}_{10} \mathrm{G}_{2}$ is cyclic and rigid. These differences not only result in different hydration states, but also different packing conformations and, consequently, modifications in the phase behavior of the system as a function of the composition. The main aim of 
the present study is to characterize the phase behavior, by evaluating of the thermodynamic parameters of the clouding phenomenon, in order to obtain information about the interactions involved in the process.

Figure 1. Molecular structures of the surfactants used in this study.<smiles>CCCCCCCCCC(=O)N(C)CC(O)C(O)C(O)C(O)CO</smiles>

$N$-decanoyl-N-methylglucamide (MEGA-10)

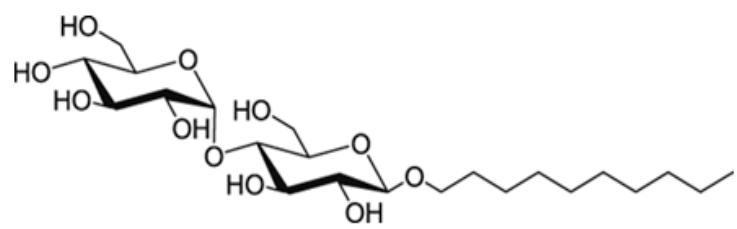

n-decyl- $\beta$-D-maltoside $\left(\mathrm{C}_{10} \mathrm{G}_{2}\right)$

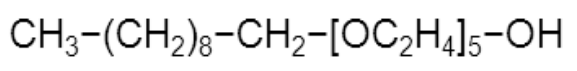

Pentaoxyethylene monodecyl ether $\left(\mathrm{C}_{10} \mathrm{E}_{5}\right)$

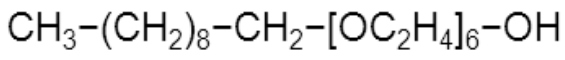
Hexaoxyethylene monodecyl ether $\left(\mathrm{C}_{10} \mathrm{E}_{6}\right)$

The outline of this paper is as follows: firstly, we measured the cloud point temperature $\left(T_{C P}\right)$ across the whole composition range, both in the presence and absence of $\mathrm{NaCl}$. Secondly, using a classical phase-separation model, we obtained the energy parameters associated with the clouding phenomenon.

\section{Results and Discussion}

\subsection{Cloud Point Temperatures}

Even though sugar-based surfactants are non-ionic, their properties are found to be quite different from those of commonly used non-ionic ethoxylated surfactants. Particularly, sugar surfactants show a greater tolerance to the temperature changes and to the presence of electrolytes. Here we discuss the results obtained for the temperature at which phase separation occurs in the mixed micelles solutions studies. Figure 2 shows plots of cloud point temperature as a function of the mole fraction of ethoxylated surfactant, $\alpha_{2}$, in the absence of $\mathrm{NaCl}$ for $\mathrm{C}_{10} \mathrm{G}_{2} / \mathrm{C}_{10} \mathrm{E}_{5}, \mathrm{C}_{10} \mathrm{G}_{2} / \mathrm{C}_{10} \mathrm{E}_{6}, \mathrm{MEGA}-10 / \mathrm{C}_{10} \mathrm{E}_{5}$ and MEGA-10/ $\mathrm{C}_{10} \mathrm{E}_{6}$ mixtures. In all the cases, the total surfactant concentration was $20 \mathrm{mM}$. In the phase diagram, below each curve exists only one liquid phase-(i.e., the micellar phase) —whereas two coexisting liquid phases are present in the region above each curve, a surfactant-rich micellar phase and a water phase. In Figure 2 one can immediately notice that in all cases the cloud point temperature increases with the percentage of sugar-based surfactant in the system. We observed that mixed micelle solutions, when $\alpha_{2}<0.6$, were completely miscible in water up to $369 \mathrm{~K}$ (i.e., phase separation did not occur), whereas clouding phenomena were seen for mixtures of MEGA-10 with $\alpha_{2} \geq 0.4$.

The cloud point of a nonionic surfactant depends on the balance between the hydrophilic and hydrophobic interactions and is very sensitive to the presence of additives [12]. Indeed the clouding phenomenon is used to assess the hydrophilic properties of nonionic surfactants [13]. Aqueous solution of these surfactants relies on the formation of hydrogen bonds between the surfactant's hydrophilic headgroups and the water molecules. It is widely assumed that phase separation is caused by the efficient dehydration of the hydrophilic portion of micelles at higher temperatures, decreasing the 
repulsive interactions which maintain micelles as discrete individuals and thus facilitates the formation of large aggregates [4].

Figure 2. Cloud point temperature as a function of mole fraction of ethoxylated surfactant in the bulk, $\alpha_{2}$, in pure water.

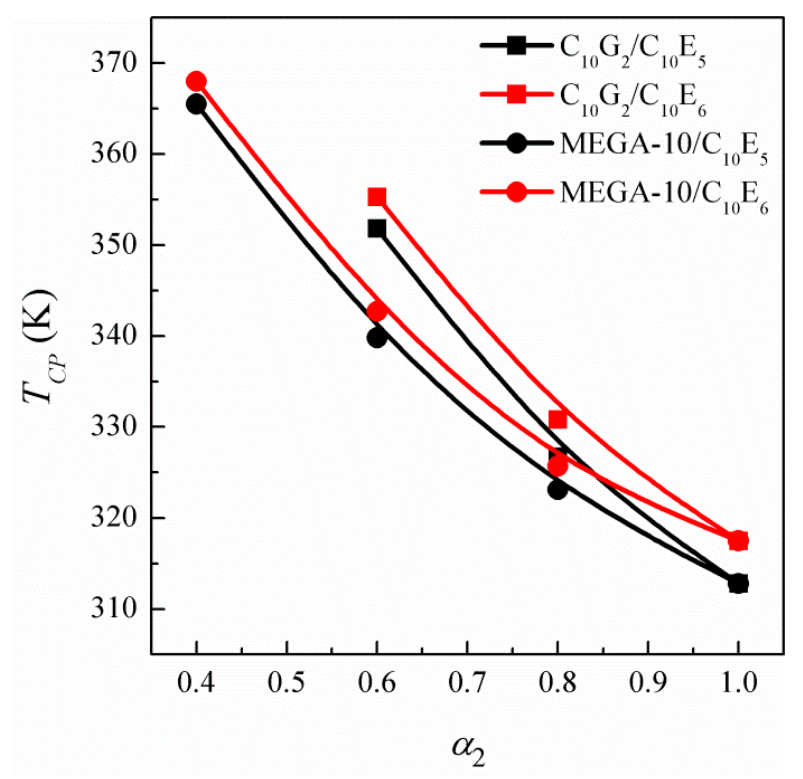

Small-angle neutron scattering studies by Goyal et al. showed that at higher temperatures the hydration of micelles formed from nonionic surfactant Triton X-100 decreases and thereby reduces the screening of the van der Waal's interactions, therefore the interaction potential between micelles becomes more attractive as temperature increases [14]. The fact that phase separation was not observed for pure $\mathrm{C}_{10} \mathrm{G}_{2}$ or MEGA-10 micellar solutions suggests that the sugar moieties interact with water molecules more favorably than the polyoxyethylene segments of the $\mathrm{C}_{10} \mathrm{E}_{5}$ or $\mathrm{C}_{10} \mathrm{E}_{6}$ surfactants, and so this prevents any significant dehydration of the sugar moieties in the mixed micelle. In fact, the correlation observed between the cloud point and the sugar surfactant content mixed surfactant systems suggests that more thermal energy is required to dehydrate the micelle due to the increased participation of sugar-based monomers in the mixed micelle, hence clouding occurs at higher temperatures. Despite the temperature increase, the sugar-based surfactants retain their hydration cospheres in the micellar interfacial microenvironment. It has been documented that the sugar headgroup is responsible for strong perturbations of the water structure at the micelle surface and it affects the formation of a large hydrogen bond network at the micelle surface between water and the headgroups, and within the headgroups themselves [15]. It is worth noting that surfactants with hydroxyl groups, such as MEGA-10 or $\mathrm{C}_{10} \mathrm{G}_{2}$, possess a greater hydrophilicity than those containing polyoxyethylene groups [16]. The greater hydrophilicity of sugar-based surfactants arises from the fact that each of their hydroxyl groups can form as many as three hydrogen bonds in aqueous media, whereas the oxyethylene group of ethoxylated surfactants only forms two H-bonds per group [17]. On the other hand, the cloud point of micellar solutions of $\mathrm{C}_{10} \mathrm{G}_{2}$ is higher than that of MEGA-10 mixtures. These results could indicate that dehydration of the $\mathrm{C}_{10} \mathrm{G}_{2}$ sugar moieties requires more thermal energy than the sugar moieties of MEGA-10. A molecule of $\mathrm{C}_{10} \mathrm{G}_{2}$ has seven hydroxyl groups whereas a MEGA-10 molecule possesses just five hydroxyl groups and so the extent of hydrogen 
bonding between the surfactant and solvating water molecules is lower in the case of MEGA 10. Another interesting conclusion that can be deduced from Figure 2 is that for a fixed value of $\alpha_{2}$ the mixtures of either of the sugar surfactants with $\mathrm{C}_{10} \mathrm{E}_{6}$ present a higher cloud point temperature than the equivalent mixtures with $\mathrm{C}_{10} \mathrm{E}_{5}$. The presence of one more oxyethylene group in the $\mathrm{C}_{10} \mathrm{E}_{6}$ surfactant molecule means the resulting mixed surfactant system has a higher hydrophilicity, which in turn leads to an increased cloud point temperature. To determine the effect that the presence of an electrolyte has on phase separation, we prepared equivalent systems with $1 \mathrm{M} \mathrm{NaCl}$. Figure 3 gives the plots of the cloud point temperature as a function of $\alpha_{2}$ in the presence of electrolyte.

Figure 3. Cloud point temperature as a function of mole fraction of ethoxylated surfactant in the bulk, $\alpha_{2}$, in $1 \mathrm{M} \mathrm{NaCl}$.

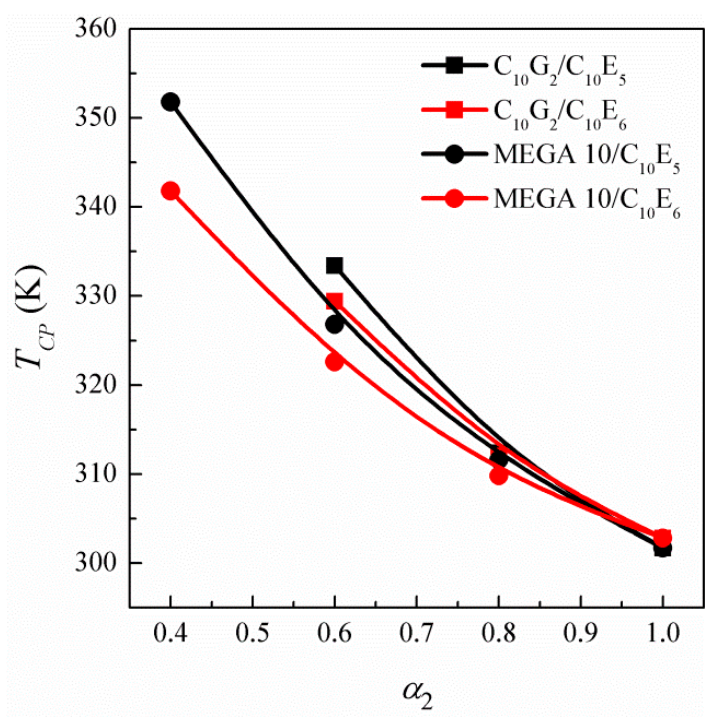

A noteworthy feature of this figure is that the cloud point temperatures of the mixed micelle systems decrease markedly in the presence of salt. This reduction in the cloud points indicates that $\mathrm{NaCl}$ has a salting-out effect because the temperature ranges in which clear solutions prevail are reduced. $\mathrm{NaCl}$ is considered to be a water-structure maker and competes for the water molecules associated with the micelles, thus promoting the dehydration of the micelles [18]. The salt changes the solvent structure and/or the extent of hydration of the clouding species meaning the micelles can approach each other more easily, leading to aggregation and the formation of large micelles. We define the cloud point shift value, $\Delta$, as being the difference between the cloud points of mixed surfactant solutions in the presence and in the absence of $\mathrm{NaCl}$. This parameter is a sensitive indicator of the $\mathrm{NaCl}$ capacity to change the cloud point of the micellar solution. The values of $\Delta$ for the mixed micelle systems are reported in Table 1 . The table show that the $\Delta$ parameter increases in the micellar solution, in absolute value, with decreasing bulk mole fraction $\left(\alpha_{2}\right)$ of each ethoxylated surfactant for a given sugar-based surfactant (MEGA-10 or $\mathrm{C}_{10} \mathrm{G}_{2}$ ). This increase in $\Delta$ is greater for $\mathrm{C}_{10} \mathrm{E}_{6}$ than for $\mathrm{C}_{10} \mathrm{E}_{5}$. Neto et al. observed that the cloud point reduction for polyoxyethylene surfactant micellar solutions in the presence of $\mathrm{KCl}$ is greater with each increase in the number of ethylene oxide units [19].

If we examine the trends in the cloud point shifts for a given ethoxylated surfactant and at a fixed value of $\alpha_{2}$, it is apparent that $\Delta$ is dependent on the nature of the sugar-based surfactant, being higher 
for $\mathrm{C}_{10} \mathrm{G}_{2}$ than for MEGA-10. This result suggests that the presence of $\mathrm{NaCl}$ in the solution affects the water structure of both the ethoxylated and sugar surfactants in the mixed micelles.

Table 1. Cloud point shift values, $\Delta$, for the studied mixtures.

\begin{tabular}{cccc|cccc}
\hline \multicolumn{3}{c|}{$\mathbf{C}_{\mathbf{1 0}} \mathbf{G}_{\mathbf{2}}$ /Ethoxylated Surfactant } & \multicolumn{4}{c}{ MEGA-10/Ethoxylated Surfactant } \\
\hline$\alpha_{\mathrm{C} 10 \mathrm{E} 5}$ & $\Delta(\mathrm{K})$ & $\alpha_{\mathrm{C} 10 \mathrm{E} 6}$ & $\Delta(\mathrm{K})$ & $\alpha_{\mathrm{C} 10 \mathrm{E} 5}$ & $\Delta(\mathrm{K})$ & $\alpha_{\mathrm{C} 10 \mathrm{E} 6}$ & $\Delta(\mathrm{K})$ \\
\hline 1 & -11.1 & 1 & -14.7 & 1 & -11.1 & 1 & -14.7 \\
0.8 & -14.3 & 0.8 & -18.8 & 0.8 & -11.5 & 0.8 & -15.9 \\
0.6 & -18.4 & 0.6 & -25.9 & 0.6 & -13.0 & 0.6 & -20.1 \\
& & & & 0.4 & -13.7 & 0.4 & -26.2 \\
\hline
\end{tabular}

The capacity of $\mathrm{NaCl}$ to reduce the cloud point temperature depends on the hydrophilicity of the surfactant molecule. All these observations are of interest as an ability to control the cloud point by varying the micellar composition or by the addition of electrolyte could be used to optimize conditions and efficiencies in applications where phase separation is either required or to be avoided. It should be noted that the effects of electrolyte on the phase separation of sugar-based surfactants have not been thoroughly examined in the literature.

\subsection{Thermodynamic Parameters at the Cloud Point}

All physicochemical processes are energetically controlled. The formation of clusters or aggregates of micelles at the cloud point is obviously guided by thermodynamic principles. At the phase separation temperature, the clouding components release their solvated water molecules and separate out from solution this can be considered as the limit of solubility [6-8,20,21]. As phase separation is a reversible process, the chemical potential of species should be equal between surfactant-rich and surfactant-poor phases. The standard Gibbs energy of phase separation (or clouding) $\Delta G_{C P}^{0}$, can then be evaluated using the well-known equation [6-8,20,21]:

$$
\Delta G_{C P}^{0}=-R T_{C P} \ln x_{S}
$$

where $R$ is the gas constant, $x_{S}$ is the mole fraction of the ethoxylated surfactant, $\mathrm{C}_{10} \mathrm{E}_{5}$ or $\mathrm{C}_{10} \mathrm{E}_{6}$, and $T_{C P}$ is the cloud point temperature in Kelvin. The standard enthalpy change of phase separation, $\Delta H_{C P}^{0}$, and the standard entropy change of phase separation, $\Delta S_{C P}^{0}$, can be calculated from the following equations:

$$
\begin{gathered}
\Delta H_{C P}^{0}=-T_{C P}^{2}\left[\frac{d\left(\Delta G_{C P}^{0} / T_{C P}\right)}{d T_{C P}}\right] \\
T_{C P} \Delta S_{C P}^{0}=\Delta H_{C P}^{0}-\Delta G_{C P}^{0}
\end{gathered}
$$

According to Equation (2), $\Delta H_{C P}^{0}$ can be extracted from the slope of a plot of $\Delta G_{C P}^{0} / T_{C P} v s$. $T_{C P}$. Figures 4 and 5 depict the change of $\Delta G_{C P}^{0} / T_{C P}$ with $T_{C P}$ for all micellar systems prepared in pure water and those prepared in the presence of $1 \mathrm{M} \mathrm{NaCl}$, respectively.

As can be seen from these figures, the data fit a straight line $(r>0.998)$. The values of $\Delta G_{C P}^{0}, \Delta H_{C P}^{0}$ and $T_{C P} \Delta S_{C P}^{0}$ for the studied systems in the absence and presence of $\mathrm{NaCl}$ are given 
in Tables 2 and 3. The positive values of $\Delta G_{C P}^{0}$ for all the mixed systems illustrate that the process is non-spontaneous (as it is caused by desolvation the micelles using thermal energy). The values of $\Delta G_{C P}^{0}$ vary moderately across a narrow range. As a general trend one can observe that the phase separation becomes energetically less favorable as the proportion of the ethoxylated surfactant, $\mathrm{C}_{10} \mathrm{E}_{5}$ or $\mathrm{C}_{10} \mathrm{E}_{6}$, in the mixed micelles decreases. The tables indicate that for a given ethoxylated surfactant at a fixed value of $\alpha_{2}$ the magnitude of $\Delta G_{C P}^{0}$ is slightly higher for mixed micelles with $\mathrm{C}_{10} \mathrm{G}_{2}$ than for MEGA-10, showing that phase separation of micellar solutions with $\mathrm{C}_{10} \mathrm{G}_{2}$ requires a greater input of thermal energy. These results confirm that phase separation is thermodynamically less favored as the hydrophilicity of the surfactant headgroup increases. It is noteworthy that the presence of electrolyte in the micellar solution improves the spontaneity of the clouding phenomenon for both sugar surfactants (i.e., $\Delta G_{C P}^{0}$ values are smaller for a fixed value of $\alpha_{2}$ ).

Figure 4. Plots of $\Delta G_{C P}^{0} / T_{C P}$ vs. $T_{C P}$ for MEGA-10/ $\mathrm{C}_{10} \mathrm{E}_{5}, \mathrm{MEGA}-10 / \mathrm{C}_{10} \mathrm{E}_{6}, \mathrm{C}_{10} \mathrm{G}_{2} / \mathrm{C}_{10} \mathrm{E}_{5}$ and $\mathrm{C}_{10} \mathrm{G}_{2} / \mathrm{C}_{10} \mathrm{E}_{6}$ systems in pure water.

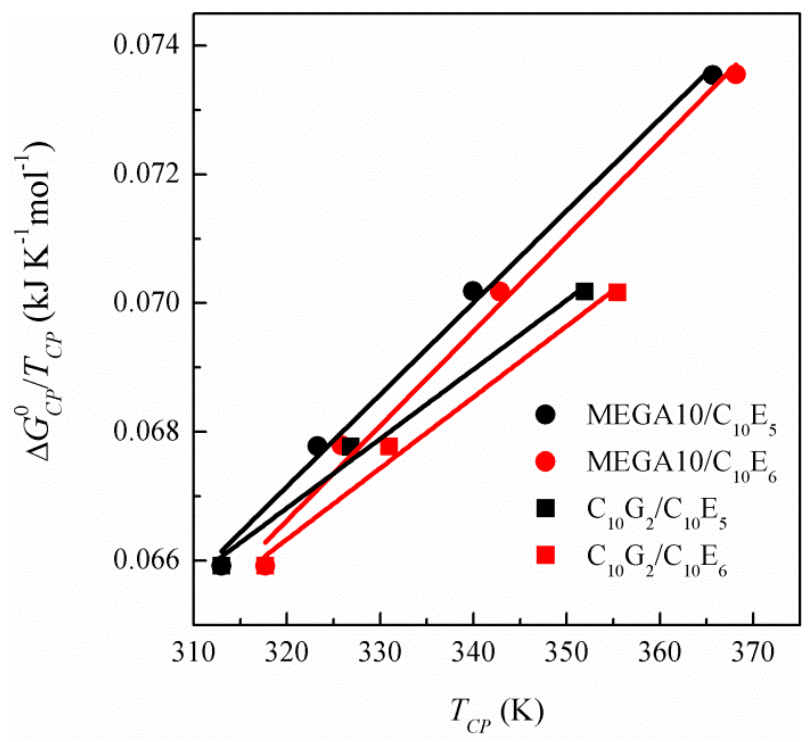

Figure 5. Plots of $\Delta G_{C P}^{0} / T_{C P}$ vs. $T_{C P}$ for MEGA-10/ $\mathrm{C}_{10} \mathrm{E}_{5}$, MEGA-10/ $\mathrm{C}_{10} \mathrm{E}_{6}, \mathrm{C}_{10} \mathrm{G}_{2} / \mathrm{C}_{10} \mathrm{E}_{5}$ and $\mathrm{C}_{10} \mathrm{G}_{2} / \mathrm{C}_{10} \mathrm{E}_{6}$ systems in the presence of $1 \mathrm{M} \mathrm{NaCl}$.

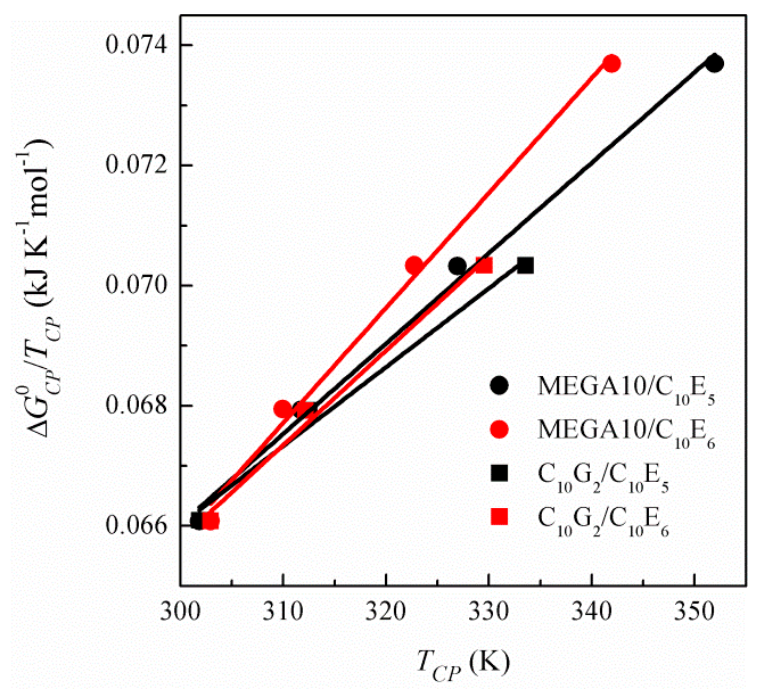


Table 2. Thermodynamic parameters of $\mathrm{C}_{10} \mathrm{G}_{2}$ /ethoxylated surfactant micelles at the cloud point temperature in pure water and in the presence of $1 \mathrm{M} \mathrm{NaCl}$.

\begin{tabular}{|c|c|c|c|c|c|c|c|}
\hline \multicolumn{5}{|c|}{$\mathrm{C}_{10} \mathrm{G}_{2} / \mathrm{C}_{10} \mathrm{E}_{5}$} & \multicolumn{3}{|c|}{$\mathrm{C}_{10} \mathrm{G}_{2} / \mathrm{C}_{10} \mathrm{E}_{6}$} \\
\hline$[\mathrm{NaCl}](\mathrm{M})$ & $\boldsymbol{\alpha}_{2}$ & $\begin{array}{c}\Delta G_{C P}^{0} \\
(\mathbf{k J} / \mathbf{m o l})^{\mathbf{a}}\end{array}$ & $\begin{array}{c}\Delta H_{C P}^{0} \\
(\mathbf{k J} / \mathbf{m o l})\end{array}$ & $\begin{array}{c}T_{C P} \Delta S_{C P}^{0} \\
(\mathbf{k J} / \mathbf{m o l}) \\
\mathbf{c}\end{array}$ & $\begin{array}{c}\Delta G_{C P}^{0} \\
(\mathbf{k J} / \mathbf{m o l})^{\mathbf{a}}\end{array}$ & $\begin{array}{c}\Delta H_{C P}^{0} \\
(\mathbf{k J} / \mathbf{m o l})\end{array}$ & $\begin{array}{c}T_{C P} \Delta S_{C P}^{0} \\
(\mathbf{k J} / \mathbf{m o l})^{\mathbf{c}}\end{array}$ \\
\hline \multirow{3}{*}{0} & 1 & 20.6 & -10.5 & -31.1 & 20.9 & -11.1 & -32.0 \\
\hline & 0.8 & 22.2 & -11.5 & -33.7 & 22.4 & -12.1 & -34.5 \\
\hline & 0.6 & 24.7 & -13.3 & -38.0 & 24.9 & -14.0 & -38.9 \\
\hline \multirow{3}{*}{1} & 1 & 20.0 & -11.9 & -31.9 & 20.0 & -14.4 & -34.4 \\
\hline & 0.8 & 21.2 & -12.8 & -34.0 & 21.2 & -15.3 & -36.5 \\
\hline & 0.6 & 23.5 & -14.6 & -38.1 & 23.2 & -17.1 & -40.3 \\
\hline
\end{tabular}

Table 3. Thermodynamic parameters of MEGA-10/ethoxylated surfactant micelles at the cloud point temperature in pure water and in the presence of $1 \mathrm{M} \mathrm{NaCl}$.

\begin{tabular}{|c|c|c|c|c|c|c|c|}
\hline \multicolumn{5}{|c|}{ MEGA-10/C $10 E_{5}$} & \multicolumn{3}{|c|}{ MEGA-10/C $\mathbf{C}_{10} \mathbf{E}_{6}$} \\
\hline$[\mathrm{NaCl}](\mathrm{M})$ & $\alpha_{2}$ & $\begin{array}{c}\Delta G_{C P}^{0} \\
(\mathbf{k J} / \mathbf{m o l})^{\mathbf{a}}\end{array}$ & $\begin{array}{c}\Delta H_{C P}^{0} \\
(\mathbf{k J} / \mathbf{m o l})^{\mathbf{b}}\end{array}$ & $\begin{array}{c}T_{C P} \Delta S_{C P}^{0} \\
(\mathbf{k J} / \mathbf{m o l})^{\mathbf{c}}\end{array}$ & $\begin{array}{c}\Delta G_{C P}^{0} \\
(\mathbf{k J} / \mathbf{m o l})^{\mathbf{a}}\end{array}$ & $\begin{array}{c}\Delta H_{C P}^{0} \\
(\mathbf{k J} / \mathbf{m o l})^{\mathbf{b}}\end{array}$ & $\begin{array}{c}T_{C P} \Delta S_{C P}^{0} \\
(\mathbf{k J} / \mathbf{m o l})^{\mathbf{c}}\end{array}$ \\
\hline \multirow{4}{*}{0} & 1 & 20.6 & -14.0 & -34.6 & 20.9 & -14.8 & -35.7 \\
\hline & 0.8 & 21.9 & -14.9 & -36.8 & 22.1 & -15.6 & -37.7 \\
\hline & 0.6 & 23.9 & -16.5 & -40.4 & 24.1 & -17.3 & -41.4 \\
\hline & 0.4 & 26.9 & -19.1 & -46.0 & 27.1 & -20.0 & -47.1 \\
\hline \multirow{4}{*}{1} & 1 & 19.9 & -13.7 & -33.6 & 20.0 & -17.6 & -37.6 \\
\hline & 0.8 & 21.2 & -14.6 & -35.8 & 21.1 & -18.4 & -39.5 \\
\hline & 0.6 & 23.0 & -16.0 & -39.0 & 22.7 & -19.9 & -42.6 \\
\hline & 0.4 & 25.9 & -18.6 & -44.5 & 25.2 & -22.4 & -47.6 \\
\hline
\end{tabular}

Uncertainty limits ${ }^{\mathrm{a}} \pm 0.1 \mathrm{~kJ} \cdot \mathrm{mol}^{-1} ;{ }^{\mathrm{b}} \pm 1.0 \mathrm{~kJ} \cdot \mathrm{mol}^{-1}$ and $^{\mathrm{c}} \pm 1.0 \mathrm{~kJ} \cdot \mathrm{mol}^{-1}$.

As can be seen in Tables 2 and 3, the values of $T_{C P} \Delta S_{C P}^{0}$ and $\Delta H_{C P}^{0}$ are negative, the former having the greater magnitude. These results reveal that entropy dominates over the enthalpy factor in the clouding phenomenon. At the cloud point a change occurs in the balance between attractive and repulsive intermicellar interactions [22]. When phase separation occurs the water molecules become very detached from the micelles. As a consequence the repulsive interaction resulting from the structured water around the micelles decreases whereas the attractive forces (van der Waals and hydrophobic interactions), which only interact over very short distances, become increasingly more significant.

The net heat change of the clouding phenomenon is due to the different processes involved. In the initial steps of the phase separation process, the destruction of the water structure around the polyoxyethylene moieties and the sugar headgroups results in a positive entropy change (requiring the absorption of heat), followed by association of dehydrated molecules involving the release of heat $[23,24]$.

The negative values of $\Delta H_{C P}^{0}$ and $T_{C P} \Delta S_{C P}^{0}$ indicate that the association process overrides the dehydration step because the formation of larger aggregates involves the release of heat and increases the system's order $[7,8]$. Therefore, the driving force for the phase separation process is the tendency 
of dehydrated micelles to transfer from the solvent environment to a surfactant-rich phase. In addition to these two main contributing factors, hydrocarbon chains would be more closely packed in the surfactant-rich phase than in micelles. Thus, it is likely that the hydrocarbon chains contribute to the decrease in enthalpy when surfactants are transferred from micelles to the condensed phase [25]. A gain in entropy occurs when water molecules in hydration shells around the hydrophobic parts of the surfactant are released during the phase separation process, resulting in an increase in the degree of freedom. The contribution of this increase of entropy in the overall change of entropy of clouding process has to be equal for all the micellar systems because the four micelles have the same hydrophobic tail.

In all cases, the micellar solutions become slightly more ordered upon increasing the proportion of sugar-based surfactant in the mixed micelle systems, as indicated by the increasing magnitude of the $T_{C P} \Delta S_{C P}^{0}$ values, however, these values are always more negative with $\mathrm{C}_{10} \mathrm{E}_{6}$ rather than $\mathrm{C}_{10} \mathrm{E}_{5}$ surfactant system (for a given sugar surfactant). Notice that the phase separation process is more exothermic as $\alpha_{2}$ decreases, whereas the clouding process becomes less exothermic in the presence of $\mathrm{NaCl}$, probably because the heat required for the dehydration process is lower (i.e., $\mathrm{NaCl}$ facilitates the dehydration of micelles). In general, the addition of $\mathrm{NaCl}$ to micellar medium results in more order within the mixed micelle system at the cloud point.

\subsection{Enthalpy-Entropy Compensation}

In kinetics and equilibrium studies, an extra thermodynamic linear correlation between the enthalpy and entropy changes is often reported for the process involved, called the enthalpy-entropy compensation effect [26]. The compensation effect is observed when a series of structurally related substrates undergo the same general process or when the process conditions for a single substrate are changed in a systematic way [27]. This phenomenon occurs when parallel enthalpy and entropy changes compensate each other to produce minor changes in the free energy of the process. This compensation has proven to be rather common for processes or reactions occurring in aqueous media such as oxidation-reduction, hydrolysis, micellization, protein unfolding, etc. [28,29]. It is generally accepted that the main process responsible for the compensation phenomenon is the reorganization of water molecules [30].

According to the views of Lumry and Rajender, the compensation phenomenon might result from the dominant role of water as the solvent in which the processes take place [31]. These authors explained that two types of contribution influence enthalpy-entropy compensation; one arises from the solute-solute interactions (i.e., the chemical contribution) and the second stems from solute-solvent interactions (i.e., the solvation contribution). In general, the compensation phenomenon between $\Delta H_{C P}^{0}$ and $\Delta S_{C P}^{0}$ in the various processes can be described as follows:

$$
\Delta H_{C P}^{0}=\Delta H_{C P}^{*}+T_{C} \Delta S_{C P}^{0}
$$

where $T c$, known as compensation temperature, can be deduced from the plot of $\Delta H_{C P}^{0} v s . \Delta S_{C P}^{0}$ and interpreted as a characteristic of solute-solvent interactions, i.e., the arrangement of water molecules surrounding the micelles. This temperature corresponds to the particular temperature where the process is purely enthalpy-driven ( $\Delta G_{C P}^{0}=\Delta H_{C P}^{*}$ ) and it serves as the basis of comparison for differing 
examples of compensation behavior. The compensation temperature is a measure of the "dehydration" part of the clouding process $[23,25]$. The compensation temperature may be regarded as a measure of how much additional heat is required to increase the entropy change by a definite amount. For processes occurring in aqueous micellar solutions, such as phase separation, the hydration-dehydration would contribute to the entropy change [25]. Thus, in this case, the compensation temperature may become a measure of the strength of the surfactant-water interaction; high $T_{C}$ values correspond to strong surfactant-water interactions. On the other hand, the intersection of this compensation plot, $\Delta H_{C P}^{*}$, characterizes the surfactant-surfactant interactions, i.e., considered as an index for the "chemical" part of the clouding process. The thermodynamic results herein collected for the mixtures studied with and without electrolyte were tested for this correlation and are illustrated in Figure 6.

Linear regression analysis gives straight lines that fit the data well $(r>0.999)$. It has been reported that in some cases the linear relationship between enthalpy and entropy is simply a demonstration of the experimental error and hence misleading [32]. The uncertainty in the estimates of $\Delta H$ and $\Delta S$ from a linear van't Hoff plot are highly correlated. If the uncertainty is large enough, the inherent imprecision of the data will lead to a false compensation [29]. Several methods for finding a real compensation effect have been suggested in the literature. One of these methods is the regression in the coordinates $\Delta H$ vs. $\Delta G$ [33]. Our experimental values showed linear $\Delta H-\Delta G$ plots with a high correlation coefficient (plots not shown), suggesting the validity of the enthalpy-entropy compensation observed in Figure 6.

Figure 6. Enthalpy-entropy compensation plots for MEGA-10/ $\mathrm{C}_{10} \mathrm{E}_{5}, \mathrm{MEGA}-10 / \mathrm{C}_{10} \mathrm{E}_{6}$, $\mathrm{C}_{10} \mathrm{G}_{2} / \mathrm{C}_{10} \mathrm{E}_{5}$ and $\mathrm{C}_{10} \mathrm{G}_{2} / \mathrm{C}_{10} \mathrm{E}_{6}$ systems in pure water and in the presence of $1 \mathrm{M} \mathrm{NaCl}$.

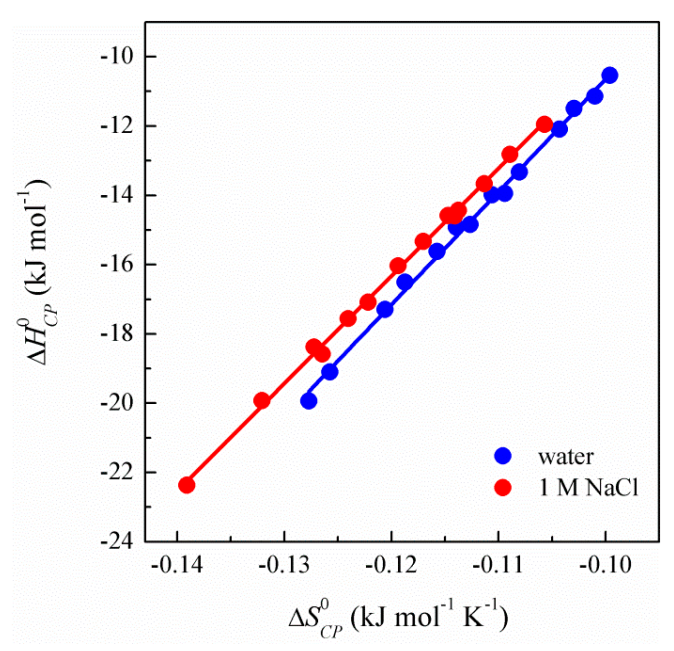

It is intriguing to note that the experimental results for the four micellar mixtures (MEGA-10/ $\mathrm{C}_{10} \mathrm{E}_{5}$, MEGA-10/ $\mathrm{C}_{10} \mathrm{E}_{6}, \mathrm{C}_{10} \mathrm{G}_{2} / \mathrm{C}_{10} \mathrm{E}_{5}$ and $\left.\mathrm{C}_{10} \mathrm{G}_{2} / \mathrm{C}_{10} \mathrm{E}_{6}\right)$ can be fitted with the same straight line. This means that the "dehydration" part of the clouding process may follow the same mechanism for all the systems studied [34]. Huang et al. found that the compensation plots for the micellization of three nonionic surfactants $\left(\mathrm{C}_{12} \mathrm{E}_{4}, \mathrm{C}_{12} \mathrm{E}_{5}\right.$ and $\left.\mathrm{C}_{12} \mathrm{E}_{6}\right)$ in aqueous solution all coincided on a single straight line, which implies that both the "desolvation" and "chemical" part of the process of micellization are independent of the size of the hydrophilic group of surfactants [35,36]. The calculated value of $T_{C}$ for pure water was $325 \pm 5 \mathrm{~K}$ and for $1 \mathrm{M} \mathrm{NaCl}$ it was $310 \pm 4 \mathrm{~K}$. It is clear that the presence of salt reduce the value 
of $T_{C}$, thus indicating that less energy is required to induce phase separation in the presence of salt. Since $T_{C}$ is found to lie well within $250-325 \mathrm{~K}$, (the identified range where solvent structural changes are associated with the micellization process, protein unfolding, etc.), it seems reasonable to suggest that the clouding process of mixed micelles is solely associated with the structural changes of water surrounding micelles [37].

The calculated $\Delta H_{C P}^{*}$ values for pure water and for $1 \mathrm{M} \mathrm{NaCl}$ were $-21.8 \pm 0.6$ and $-21.0 \pm 0.5 \mathrm{~kJ} / \mathrm{mol}$, respectively. These values clearly indicate that $\Delta H_{C P}^{*}$ is barely affected by the presence of the electrolyte, implying that the chemical part of the clouding process is practically independent of the presence of $\mathrm{NaCl}$ in the medium. On the other hand, constancy in the value of $\Delta H_{C P}^{*}$ is also expected when considering that this parameter represents the effectiveness of the surfactant's hydrophobic chain in promoting the clouding process (the same hydrophobic tail was used for all the surfactants in the study) [38].

\subsection{Changes in the Molar Heat Capacity}

The plots of $\Delta H_{C P}^{0} v s$. the cloud point temperature are found to be linear, as shown in Figures 7 and 8 $(r>0.999)$. The slope of these plots corresponds to the change in the molar heat capacity, $\Delta C_{C P}$, for the phase transition. The values for $\Delta C_{C P}$ calculated from linear regression analysis are given in Table 4 . The $\Delta C_{C P}$ parameter is a measure of the change in heat capacity between the initial state, where micelles are dispersed in the medium, and the final state, in which the micelle aggregates form a surfactant-rich phase. A negative value of $\Delta C_{C P}$ indicates that $\Delta H_{C P}^{0}$ becomes more negative as the temperature increases; that is the phase separation process is more exothermic as the cloud point temperature increases.

The change in heat capacity contains information on the variation of water-accessible polar and nonpolar region in the micellization of nonionic surfactants $[39,40]$. In particular, a negative change in the heat capacity is indicative of an aggregation process accompanied by a loss of solvating water structure [41]. It is commonly observed that the thermal denaturation of a protein is accompanied by an increase in heat capacity between the system's initial and final states. This is customarily attributed to the exposure of hydrophobic residues along the polypeptide chain to aqueous solvent [42].

Such exposure tends to reinforce the hydrogen-bonded structure of water [43]. If the clouding phenomenon involves partial destruction of the hydrogen-bonded structure of water shells surrounding the surfactant molecules, then this should be reflected in negative values of $\Delta C_{C P}$, as observed. In protein biochemistry a disorder-to-order transition generally involves formation of a more cooperative set of interactions within the protein that replaces a less cooperative set of interactions between the protein and the solvent, resulting in negative values of $\Delta C_{C P}$ [44]. Similarly, in a phase separation process, both the entropy change and the heat capacity change are negative. A noteworthy feature in Table 4 is that $\Delta C_{C P}$ is lower, in absolute values, for mixed micelles with $\mathrm{C}_{10} \mathrm{G}_{2}$ than for micelles with MEGA-10. This could indicate that the reorganization of water molecules accompanying phase separation of $\mathrm{C}_{10} \mathrm{G}_{2}$ mixed micelles is small when compared with MEGA-10 mixed micelles. It is worth pointing out that in all the measured micelle solutions the presence of $\mathrm{NaCl}$ resulted in an increase in the change of the heat capacity of the phase separation process. This trend support the idea 
of a higher destruction of the hydration layer of micelles during the clouding process in $1 \mathrm{M} \mathrm{NaCl}$ solutions, in concordance with a lower cloud point temperature.

Figure 7. Enthalpy change as a function of cloud point temperature for MEGA- $10 / \mathrm{C}_{10} \mathrm{E}_{5}$, MEGA-10/ $\mathrm{C}_{10} \mathrm{E}_{6}, \mathrm{C}_{10} \mathrm{G}_{2} / \mathrm{C}_{10} \mathrm{E}_{5}$ and $\mathrm{C}_{10} \mathrm{G}_{2} / \mathrm{C}_{10} \mathrm{E}_{6}$ systems in pure water.

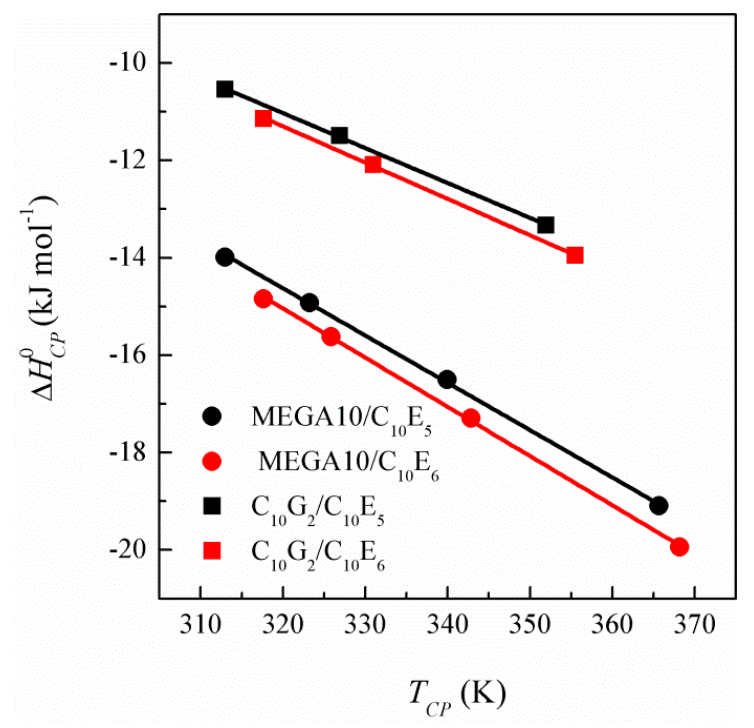

Figure 8. Enthalpy change as a function of cloud point temperature for MEGA-10/ $\mathrm{C}_{10} \mathrm{E}_{5}$, MEGA-10/ $\mathrm{C}_{10} \mathrm{E}_{6}, \mathrm{C}_{10} \mathrm{G}_{2} / \mathrm{C}_{10} \mathrm{E}_{5}$ and $\mathrm{C}_{10} \mathrm{G}_{2} / \mathrm{C}_{10} \mathrm{E}_{6}$ systems in $1 \mathrm{M} \mathrm{NaCl}$.

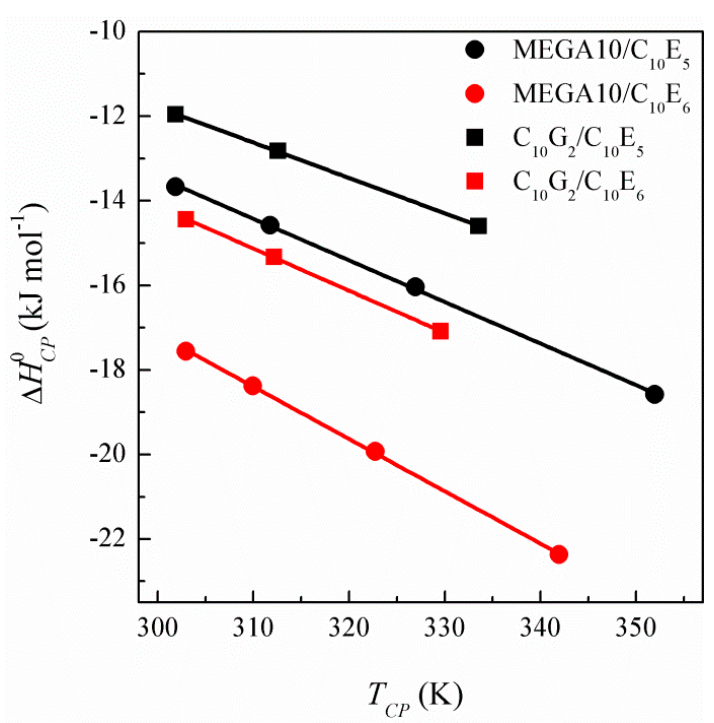

Table 4. $\Delta C_{C P}$ values for the mixtures MEGA-10/ $\mathrm{C}_{10} \mathrm{E}_{5}$, MEGA-10/ $\mathrm{C}_{10} \mathrm{E}_{6}, \mathrm{C}_{10} \mathrm{G}_{2} / \mathrm{C}_{10} \mathrm{E}_{5}$ and $\mathrm{C}_{10} \mathrm{G}_{2} / \mathrm{C}_{10} \mathrm{E}_{6}$, in pure water and in the presence of $1 \mathrm{M} \mathrm{NaCl}$.

\begin{tabular}{|c|c|c|}
\hline Mixture & $\begin{array}{c}\Delta C_{C P}\left(\mathbf{k J} \cdot \mathbf{m o l}^{-1} \cdot \mathbf{K}^{-\mathbf{1}}\right) \\
\text { Water }\end{array}$ & $\begin{array}{c}\Delta C_{C P}\left(\mathbf{k J} \cdot \mathrm{mol}^{-1} \cdot \mathbf{K}^{-1}\right) \\
1 \mathrm{M} \mathrm{NaCl}\end{array}$ \\
\hline MEGA- $10 / \mathrm{C}_{10} \mathrm{E}_{5}$ & $-0.097 \pm 0.002$ & $-0.099 \pm 0.002$ \\
\hline MEGA-10/C ${ }_{10} \mathrm{E}_{6}$ & $-0.101 \pm 0.001$ & $-0.124 \pm 0.001$ \\
\hline $\mathrm{C}_{10} \mathrm{G}_{2} / \mathrm{C}_{10} \mathrm{E}_{5}$ & $-0.072 \pm 0.001$ & $-0.084 \pm 0.001$ \\
\hline $\mathrm{C}_{10} \mathrm{G}_{2} / \mathrm{C}_{10} \mathrm{E}_{6}$ & $-0.075 \pm 0.001$ & $-0.100 \pm 0.001$ \\
\hline
\end{tabular}




\section{Experimental Section}

\subsection{Materials}

Table 5 contains the main characteristics of the surfactant samples used in the present study. Due to their high purity grade, they were used as received. Aqueous stock solutions of surfactants were prepared by weight. Working samples with a lower concentration $(20 \mathrm{mM})$ were prepared daily from the stock solutions. The bulk composition of these solutions is expressed in terms of mole fraction of the ethoxylated surfactant, $\alpha_{2}$, which is defined by the relationship $\left[\mathrm{C}_{10} \mathrm{E}_{\mathrm{i}}\right] /([$ sugar surfactant $]+$ $\left[\mathrm{C}_{10} \mathrm{E}_{\mathrm{i}}\right]$ ), where [sugar surfactant] is the molar concentration of MEGA-10 or $\mathrm{C}_{10} \mathrm{G}_{2}$ and $\left[\mathrm{C}_{10} \mathrm{E}_{\mathrm{i}}\right]$ is the molar concentration of the ethoxylated surfactant $\left(\mathrm{C}_{10} \mathrm{E}_{5}\right.$ or $\left.\mathrm{C}_{10} \mathrm{E}_{6}\right)$. The ultrapure water (resistivity $\sim 18 \mathrm{M} \Omega \cdot \mathrm{cm}$ ) used to prepare all the solutions was obtained by passing pure water from a Millipore Elix system through an ultra-high quality Millipore Synergy purification system.

Table 5. Surfactants used in the present study.

\begin{tabular}{ccccc}
\hline Surfactant & Abbreviation & Manufacturer & Grade & Mass Fraction Purity \\
\hline$n$-decyl- $\beta$-D-maltoside & $\mathrm{C}_{10} \mathrm{G}_{2}$ & Anatrace & Anagrade & $\geq 0.99$ \\
$N$-decanoyl- $N$-methylglucamide & $\mathrm{MEGA}-10$ & Sigma-Aldrich & BioXtra & $\geq 0.99$ \\
Pentaoxyethylene monodecyl ether & $\mathrm{C}_{10} \mathrm{E}_{5}$ & Sigma-Aldrich & BioXtra & $\geq 0.98$ \\
Hexaoxyethylene monodecyl ether & $\mathrm{C}_{10} \mathrm{E}_{6}$ & Sigma-Aldrich & BioXtra & $\geq 0.98$ \\
\hline
\end{tabular}

\subsection{Method}

Accurate cloud point values were obtained by noting the temperature at which the continuously heated solution suddenly became turbid. For this purpose, a known volume of the clouding species with a selected concentration $(20 \mathrm{mM})$ was introduced in a transparent test tube and placed in a thermostatted water bath. The temperature was increased under controlled conditions of constant stirring. Heating was regulated to approx. $0.5^{\circ} \mathrm{C} / \mathrm{min}$. when nearing the expected cloud point. The point of phase separation was visually observed and the temperature at the start of the phenomenon noted. Heating was then stopped and the system was allowed to cool. The temperature at which the turbidity cleated was again noted. The mean of the two temperatures was considered to be the system's cloud point. Cloud point determination in each sample was repeated at least twice. If a good reproducibility was not observed, the experiment was repeated a third time.

\section{Conclusions}

For a given sugar/polyoxyethylene system the cloud point of mixed micelle solutions was found to increase with an increasing proportion of the sugar-based surfactant. At a fixed value of the proportion of the polyoxyethylene-based surfactant, the MEGA-10 surfactant lowers the cloud point more effectively than the $\mathrm{C}_{10} \mathrm{G}_{2}$ surfactant. This fact is due to greater hydrophilic character of the $\mathrm{C}_{10} \mathrm{G}_{2}$ molecule. We observed that the cloud point temperature depends on the hydrophilic nature of surfactant molecules in the mixed micelle systems; the cloud point temperature was higher for more hydrophilic surfactant. On the other hand, the addition of $\mathrm{NaCl}$ to mixed micelle solutions decreased the cloud point temperature, suggesting that the presence of electrolyte produces a remarked alteration 
in the hydration layer of micelles. Thermodynamic analysis of the parameters that characterize the phase separation has also been conducted. The energetic parameters reveal that the clouding process is controlled by the entropy factor rather than the enthalpy term. Note that the overall micellar system is in an ordered state at the cloud point, as evidenced by the negative values of $\Delta S_{C P}^{0}$ for all systems studied. This result is in concordance with the observed negative change in the heat capacity. The final state in the phase separation becomes slightly more ordered upon increasing the proportion of sugar-based surfactant in the mixed micelles. When the mixed micelles are composed of $\mathrm{C}_{10} \mathrm{E}_{5}$ surfactant the final micellar solution is less ordered. The net heat change of phase separation is negative. This exothermic nature of the clouding process is due to the aggregation of weakly hydrated micelles and their phasing out into the condensed phase. More heat is released in the clouding process for the mixed micelle solutions with a lower proportion of polyoxyethylene surfactant and in the presence of electrolyte. It was found that the enthalpy-entropy compensation relationship holds true for this process in all the systems we investigated. The decrease in the compensation temperature in the presence of $\mathrm{NaCl}$ is attributed to the fact that the electrolyte significantly alters the micellar hydration layer. The change in heat capacity of phase separation obtained from the linear dependence of $\Delta H_{C P}^{0}$ with cloud point temperature is negative, suggesting that the process is accompanied by a loss of the hydration layer around the micelles.

\section{Acknowledgments}

This work has been financially supported by the "Consejería de Innovación, Ciencia y Empresa de la Junta de Andalucía” (Project P07-FQM-02762).

\section{Author Contributions}

The present study was carried out with close cooperation between all three co-authors. The experimental part was mainly performed by José M. Hierrezuelo, under the supervision of José A. Molina-Bolívar and Cristóbal Carnero Ruiz, who planned the experiments and performed the thermodynamic data treatment. José A. Molina-Bolívar wrote the draft of the paper which was later revised by Cristóbal Carnero Ruiz. The final version was revised and approved by all co-authors.

\section{Conflicts of Interest}

The authors declare no conflict of interest.

\section{References}

1. Myers, D. Surfactant Science and Technology, 2nd ed.; VCH Weinheim: New York, NY, USA, 1992; pp. 1-79.

2. Holmberg, K.; Jönsson, B.; Kronberg, B.; Lindman, B. Surfactants and Polymers in Aqueous Solution, 2nd ed.; John Wiley \& Sons Ltd.: Chichester, UK, 2003; pp. 97-118.

3. Evans, D.F.; Wennerström, H. The Colloidal Domain: Where Physics, Chemistry, Biology, and Technology Meet, 2nd ed.; Wiley-VCH: Weinheim, Germany, 1999; pp. 153-216. 
4. Mukherjee, P.; Padhan, S.K.; Dash, S.; Patel, S.; Mishra, B.K. Clouding behavior in surfactant systems. Adv. Colloid Interface Sci. 2011, 162, 59-79.

5. Nazar, M.F.; Shah, S.S.; Eastoe, J.; Khan, A.M.; Shah, A. Separation and recycling of nanoparticles using cloud point extraction with non-ionic surfactant mixtures. J. Colloid Interface Sci. 2011, 363, 490-496.

6. Alam, M.S.; Mandal, A.; Mandal, A.B. Effect of $\mathrm{KCl}$ on the micellization and clouding phenomenon of the amphiphilic phenothiazine drug promethazine hydrochloride: Some thermodynamic properties. J. Chem. Eng. Data 2011, 56, 1540-1546.

7. Molina-Bolívar, J.A.; Carnero Ruiz, C. Micellar size and phase behavior in n-octyl-beta-Dthioglucoside/Triton X-100 mixtures: The effect of $\mathrm{NaCl}$ addition. Fluid Phase Equilibria 2012, $327,58-64$.

8. Molina-Bolívar, J.A.; Hierrezuelo, J.M.; Carnero Ruiz, C. Energetics of clouding and size effects in non-ionic surfactant mixtures: The influence of alkyl chain length and $\mathrm{NaCl}$ addition. J. Chem. Thermodyn. 2013, 57, 59-66.

9. Söderman, O.; Johansson, I. Polyhydroxyl-based surfactants and their physico-chemical properties and applications. Curr. Opin. Colloid Interface Sci. 2000, 4, 391-401.

10. Stubenrauch, C. Sugar surfactants-Aggregation, interfacial, and adsorption phenomena. Curr. Opin. Colloid Interfac. Sci. 2001, 6, 160-170.

11. Carnero Ruiz, C., Ed. Sugar-Based Surfactants: Fundamentals and Applications; CRC Press: Boca Raton, FL, USA, 2009.

12. Gu, T.; Galera-Gomez, P.A. The effect of different alcohols and other polar organic additives on the cloud point of Triton X-100 in water. Colloids Surf. A 1999, 147, 365-370.

13. Zhang, R.; Zhang, L.; Somasundaran, P. Study of mixtures of $n$-dodecyl- $\beta$-D-maltoside with anionic, cationic and nonionic surfactant in aqueous solutions using surface tension and fluorescence techniques. J. Colloid Interface Sci. 2004, 278, 453-460.

14. Goyal, P.S.; Menon, S.V.; Dasannacharya, B.A.; Thiyagarajan, P. Small-angle neutron-scattering study of micellar structure and interparticle interactions in Triton X-100 solutions. Phys. Rev. E 1995, 51, 2308-2315.

15. Abel, S.; Dupradeau, F.Y.; Raman, E.P.; MacKerell, A.D.; Marchi, M. Molecular simulations of dodecyl- $\beta$-maltoside micelles in water: Influence of the headgroup conformation and force field parameters. J. Phys. Chem. B 2011, 115, 487-499.

16. Shinoda, K.; Carlsson, A.; Lindman, B. On the importance of hydroxyl groups in the polar head-group of nonionic surfactants and membrane liquids. Adv. Colloid Interface Sci. 1996, 64, 253-271.

17. Okawauchi, M.; Hagio, M.; Ikawa, Y.; Sugihara, G.; Murata, Y.; Tanaka, M. A light-scattering study of temperatura effect on micelle formation of n-alkanoyl-n-methylglucamines in aqueous-solution. Bull. Chem. Soc. Jpn. 1987, 60, 2718-2725.

18. Alam, M.S.; Naqvi, A.Z.; Kabir-ud-Din. Influence of additives on the clouding phenomenon of chlorpromazine hydrochloride solutions. Colloids Surf. B 2008, 63, 122-128.

19. Curbelo, F.; Garnica, A.; Neto, E. Salinity effect in cloud point phenomena by nonionic surfactants used in enhanced oil recovery tests. Pet. Sci. Technol. 2013, 31, 1544-1552. 
20. Batigöc, C.; Akbas, H.; Boz, M. Thermodynamics of non-ionic surfactant Triton X-100-cationic surfactants mixtures at the cloud point. J. Chem. Thermodyn. 2011, 43, 1800-1803.

21. Darshak, B.; Kalpana, C.M.; Jigisha, P. Studies on surfactant-ionic liquid interaction on clouding behavior and evaluation of thermodynamic parameters. J. Surfactants Deterg. 2013, 16, 547-557.

22. DeGiorgio, V.; Piazza, R.; Corti, M.; Minero, C. Critical properties of nonionic micellar solutions. J. Chem. Phys. 1985, 82, 1025-1031.

23. Van Bommel, A.; Palepu, R.M. n-Alkanol induced clouding of Brij 56 and the energetics of the process. Colloids Surf. A 2004, 233, 109-115.

24. Sanan, R.; Mahajan, R.K. Polyethylene glycol assisted micellar, interfacial and phase separation studies of triblock copolymer-nonionic surfactant mixtures. Colloids Surf. A 2013, 433, 145-153.

25. Inoue, T.; Ohmura, H.; Murata, D. Cloud point temperature of polyoxyethylene-type nonionic surfactants and their mixtures. J. Colloid Interface Sci. 2003, 258, 374-382.

26. Kundu, K.; Bidyut, K.P. Interfacial composition, thermodynamic properties and structural parameters of water-in-oil microemulsions stabilized by 1-pentanol and mixed anionic + polyoxyethylene type nonionic surfactants. Colloid Polym. Sci. 2013, 291, 613-632.

27. Hejri, A.; Gharanjig, K.; Khosravi, A.; Hejazi, M. Effect of surfactants on kinetics of $\beta$-carotene photodegradation in emulsions. Chem. Eng. Commun. 2013, 200, 437-447.

28. Fei, L.; Lijuan, S.; Yingqiu, G.; Xiujie, Y.; Liqiang, Z. Aggregation behavior of alkyl triphenyl phosphonium bromides in aprotic and protic ionic liquids. Colloid Polym. Sci. 2013, 291, 2375-2384.

29. Liu, L.; Guo, Q.X. Isokinetic relationship, isoequilibrium relationship, and enthalpy-entropy compensation. Chem. Rev. 2001, 101, 673-696.

30. Battistuzzi, G.; Bellei, M.; Borsari, M.; Canters, G.W.; Waals, E.; Jeuken, L.J.C.; Ranieri, A.; Sola, M. Control of metalloprotein reduction potential: Compensation phenomena in the reduction thermodynamics of blue copper proteins. Biochemistry 2003, 42, 9214-9220.

31. Lumry, R.; Rajender, S. Enthalpy-entropy compensation phenomena in water solutions of proteins and small molecules: A ubiquitous properly of water. Biopolymers 1970, 9, 1125-1227.

32. Sharp, K. Entropy-enthalpy compensation: Fact or artifact? Protein Sci. 2001, 10, 661-667.

33. Exner, O. Statistics of the enthalpy-entropy relationship. III. Processing of calorimetric data. Collect. Czech. Chem. Commun. 1973, 38, 799-812.

34. Wei, D.; Kang, L.; Xiaojun, L.; Huoxin, L.; Chongfu, L.; Tao, Y.; Guangmiao, Q. Micellization behavior of ionic liquid surfactants with two hydrophobic tail chains in aqueous solution. J. Appl. Polym. Sci. 2013, 129, 2057-2062.

35. Chen, L.J.; Lin, S.Y.; Huang, C.C.; Chen, E.M. Temperature dependence of critical micelle concentration of polyoxyethylene non-ionic surfactants. Colloid Surf. A 1998, 135, 175-181.

36. Chen, L.J.; Lin, S.Y.; Huang, C.C.; Chen, E.M. Effect of hydrophobic chain length of surfactants on enthalpy-entropy compensation of micellization. J. Phys. Chem. 1998, 102, 4350-4356.

37. Kaushal, D.; Rana, D.S.; Chauhan, M.S.; Umar, A.; Chauhan, S. The effect of sodium dodecyl sulphate on Furosemide-A cardiovascular drug in water-methanol at different temperature. J. Mol. Liq. 2013, 188, 237-244.

38. Hoque, M.A.; Hossain, M.D.; Khan, M.A. Interaction of cephalosporin drugs with dodecylmethy-lammonium bromide. J. Chem. Thermodyn. 2013, 63, 135-141. 
39. Majhi, P.R.; Blume, A. Thermodynamic characterization of temperature-induced micellization and demicellization of detergents studied by differential scanning calorimetry. Langmuir 2001, $17,3844-3851$.

40. Tsui, H.W.; Hsu, Y.H.; Wang, J.H.; Chen, L.J. Novel behavior of heat of micellization of Pluronics F68 and F88 in aqueous solutions. Langmuir 2008, 24, 13858-13862.

41. Armstrong, J.K.; Leharne, S.A.; Stuart, B.H.; Snowden, M.J.; Chowdhry, B.Z. Phase transition properties of poly(ethylene oxide) in aqueous solutions of sodium chloride. Langmuir 2001, 17, 4482-4485.

42. Armstrong, J.K.; Chowdhry, B.Z.; Snowden, M.J.; Leharne, S.A. Effect of sodium chloride upon micellization and phase separation transitions in aqueous solutions of triblock copolymers: A high-sensitivity differential scanning calorimetry study. Langmuir 1998, 14, 2004-2010.

43. Armstrong, J.K.; Chowdhry, B.Z.; O’Brien, R.; Beezer, A.; Mitchell, J.; Leharne, S.A. Scanning microcalorimetric investigations of phase transitions in dilute aqueous solutions of poly(oxypropylene). J. Phys. Chem. 1995, 99, 4590-4598.

44. Vamvaca, K.; Jelesarov, I.; Hilvert, D. Kinetics and thermodynamics of ligand binding to a molten globular enzyme and its native counterpart. J. Mol. Biol. 2008, 383, 971-977.

(C) 2014 by the authors; licensee MDPI, Basel, Switzerland. This article is an open access article distributed under the terms and conditions of the Creative Commons Attribution license (http://creativecommons.org/licenses/by/3.0/). 